\title{
Expression of hepatocyte growth factor and c-Met is characteristic of $\alpha$-fetoprotein-producing colorectal adenocarcinoma: A report of three cases
}

\author{
JUN LI ${ }^{1,2 *}$, YUE LIU ${ }^{2 *}$, JING-HONG XU ${ }^{2,3}$, ZHENG-PING XU ${ }^{4}$, SHU ZHENG ${ }^{1,2}$ and KE-FENG DING ${ }^{1,2}$ \\ ${ }^{1}$ Department of Surgical Oncology, Second Affiliated Hospital, Zhejiang University School of Medicine; ${ }^{2}$ Key Laboratory \\ of Cancer Prevention and Intervention, China National Ministry of Education; ${ }^{3}$ Department of Pathology, Second Affiliated \\ Hospital, Zhejiang University School of Medicine, Hangzhou, Zhejiang 310009; ${ }^{4}$ Department of Environmental Medicine, \\ Zhejiang University School of Medicine, Hangzhou, Zhejiang 310058, P.R. China
}

Received December 3, 2014; Accepted October 14, 2015

DOI: $10.3892 / \mathrm{ol} .2015 .3964$

\begin{abstract}
AFP)-producing colorectal adenocarcinoma is rare and typically not well recognized. In the present study, 3 cases of AFP-producing colorectal cancer are described. All 3 of these cases demonstrated increased levels of blood AFP associated with disease progression. Only case 2 exhibited classical histological hepatoid features. Following immunohistochemical tissue staining, all 3 cases were observed to be positive for AFP expression. In addition, the expression of hepatocyte growth factor (HGF), c-Met receptor and the transcription factor c-Myc were identified to be associated with the expression of AFP. The 3 cases demonstrated resistance to multiple drugs, including epidermal growth factor receptor inhibitors, despite the presence of wild-type Kirsten rat sarcoma viral oncogene homolog (K-RAS; codons 12 and 13), neuroblastoma-RAS (codons 12 and 13) and B-Raf proto-oncogene, serine/threonine kinase (V600E). We propose that hepatoid histological features or a positive AFP finding by immunohistochemistry are sufficient for a diagnosis of AFP-producing colorectal adenocarcinoma. Furthermore, we speculates that autocrine HGF/c-Met activation may be capable of inducing the dedifferentiation
\end{abstract}

Correspondence to: Professor Ke-Feng Ding, Department of Surgical Oncology, Second Affiliated Hospital, Zhejiang University School of Medicine, 88 Jiefang Road, Hangzhou, Zhejiang 310009, P.R. China

E-mail: dingkefeng@zju.edu.cn

*Contributed equally

Abbreviations: HA, hepatoid adenocarcinoma; EGFR, epidermal growth factor receptor; AFP, $\alpha$-fetoprotein; HGF, hepatocyte growth factor; S-1, tegafur/gimeracil/oteracil potassium; APA, AFP-producing adenocarcinoma

Key words: $\alpha$-fetoprotein, colorectal cancer, hepatocyte differentiation of common adenocarcinoma cells, reverting them to a cancer stem cell state and producing AFP or hepatoid differentiation. Consequently, therapy targeted to the HGF/c-Met signaling pathway may potentially be effective for the treatment of AFP-producing colorectal adenocarcinoma.

\section{Introduction}

$\alpha$-fetoprotein (AFP)-producing adenocarcinoma (APA) is a non-hepatocellular adenocarcinoma that secretes AFP. Hepatoid adenocarcinoma (HA) is similar but not identical to APA. HA is typically diagnosed when extrahepatic adenocarcinoma exhibits a specific histological appearance, including solid, trabecular and pseudogranular structures with polygonal cells, whether or not these cells are capable of producing AFP $(1,2)$. At present, to the best of our knowledge, there is no consistent description for APA/HA (3). As a result, the real incidence of APA/HA is unknown. The majority of reported cases arise from the gastrointestinal tract, especially the stomach. The proportion of APA/HAs originate from stomach has been reported to be $\sim 1-15 \%$. Moreover, the colorectal APA/HA is rare. The clinical presentation of APA/HA vary greatly depending on the anatomic location of the tumor $(1,2,4)$. Gastrointestinal APA/HA has a clinicopathological presentation that mimics primary hepatocellular carcinoma, and it possesses a poor prognosis due to the frequent occurrence of metastasis and multidrug resistance (4). Understanding the underlying mechanism of APA/HA is key for the improvement of its diagnosis and treatment. In the present report, 3 cases of colorectal APA are presented and a potential molecular etiology is proposed. The present study was approved by the Ethics Committee of the Second Affiliated Hospital, Zhejiang University School of Medicine (Hangzhou, China).

\section{Case report}

Case 1. A 66-year-old man presented at The Second Affiliated Hospital, Zhejiang University School of Medicine (Hangzhou, China) with the symptoms of melena, which had been evident for 5 years, and epigastric pain, which had been evident for 
1 month, on November 15, 2011. Hepatic flexure colon adenocarcinoma was confirmed via colonoscopy. Magnetic resonance imaging (MRI) and positron emission tomography-computed tomography (PET-CT) scanning revealed simultaneous liver and retroperitoneal lymph node metastases. Blood tests showed a carcinoembryonic antigen (CEA) concentration of $25.1 \mathrm{ng} / \mathrm{ml}$ (normal, $<5 \mathrm{ng} / \mathrm{ml}$ ), a cancer antigen 19-9 (CA19-9) concentration of $115.2 \mathrm{U} / \mathrm{ml}$ (normal, $<37 \mathrm{U} / \mathrm{ml}$ ) and an AFP concentration of $149.8 \mathrm{ng} / \mathrm{ml}$ (normal, $<20 \mathrm{ng} / \mathrm{ml}$ ), with negative hepatitis markers. The disease progressed following 4 cycles of mFOLFOX6 chemotherapy [Oxaliplatin $85 \mathrm{mg} / \mathrm{m}^{2}$ intravenously administered (IV) over $2 \mathrm{~h}$ on day 1 plus leucovorin $400 \mathrm{mg} / \mathrm{m}^{2} \mathrm{IV}$ over $2 \mathrm{~h}$ on day 1 plus 5 -FU $400 \mathrm{mg} / \mathrm{m}^{2}$ IV bolus on day 1 , then $2,400 \mathrm{mg} / \mathrm{m}^{2}$ intravenous infusion over 46 h; repeated every 2 weeks]. On February 10, 2012, the patient underwent a palliative right hemicolectomy, a small intestine mesenteric lymph node dissection and a core needle biopsy of the para-aortic lymph nodes. The pathology report revealed an invasive colonic micropapillary carcinoma accompanying the moderately-differentiated adenocarcinoma, involving 12/19 lymph nodes. The Kirsten rat sarcoma viral oncogene homolog (K-RAS) gene was wild-type on direct sequencing. On March 13, 2012, the patient's blood CEA, CA 19-9 and AFP concentrations were $8.1 \mathrm{ng} / \mathrm{ml}, 24.5 \mathrm{U} / \mathrm{ml}$ and $901.1 \mathrm{ng} / \mathrm{ml}$, respectively. The patient experienced right oculomotor nerve palsy following 4 cycles of irinotecan with 5-FU and folinic acid (FOLFIRI; irinotecan $180 \mathrm{mg} / \mathrm{m}^{2} \mathrm{IV}$ over $90 \mathrm{~min}$ on day 1 plus leucovorin $400 \mathrm{mg} / \mathrm{m}^{2} \mathrm{IV}$ over $2 \mathrm{~h}$ on day 1 plus 5 -FU $400 \mathrm{mg} / \mathrm{m}^{2} \mathrm{IV}$ bolus on day 1 , then $2,400 \mathrm{mg} / \mathrm{m}^{2} \mathrm{IV}$ infusion over $46 \mathrm{~h}$; repeat every 2 weeks) and cetuximab chemotherapy post-operatively $\left(500 \mathrm{mg} / \mathrm{m}^{2} \mathrm{IV}\right.$ over $3 \mathrm{~h}$; repeat every 2 weeks) MRI and CT scanning revealed metastasis to the clivus and involvement of the cavernous sinus. Radiotherapy (3,000 cGy in 10 fractions) directed at the bone metastases was added to the patient's treatment regimen. However, the symptoms were not alleviated and the patient suffered progressively worsening insomnia. Blood tests revealed CEA, CA19-9 and AFP concentrations of $4.6 \mathrm{ng} / \mathrm{ml}$, $9.0 \mathrm{U} / \mathrm{ml}$ and 2,554.3 $\mathrm{ng} / \mathrm{ml}$, respectively, on May 9, 2012, and $18.2 \mathrm{ng} / \mathrm{ml}, 64.0 \mathrm{U} / \mathrm{ml}$ and $7,049.1 \mathrm{ng} / \mathrm{ml}$, respectively, on June 13,2012. The patient succumbed to multiple organ failure in July 2012. Histological images of the primary tumor are presented in Fig. 1. Additional direct sequencing confirmed the wild-type N-RAS (codons 12 and 13) and BRAF (V600E) gene types of primary cancer.

Case 2. A 49-year-old man, who presented with hematochezia, was diagnosed with moderately- to poorly-differentiated rectal adenocarcinoma at a local hospital in June 2012. Hepatitis markers were identified to be negative. The patient was administered 2 cycles of mFOLFOX6 chemotherapy, followed by local radiotherapy DT $4,500 \mathrm{cGy}$ in 25 fractions. On September 7,2012, PET-CT scanning revealed a number of enlarged lymph nodes in the mesorectum and retroperitoneum, with suspicious metastases in the liver and lung, and a blood AFP concentration of $953.9 \mathrm{ng} / \mathrm{ml}$. Following 1 cycle of capecitabine plus oxaliplatin chemotherapy, the patient underwent a palliative Hartmann's procedure at our hospital on October 25, 2012. A pathological report indicated a moderately-differentiated rectal adenocarcinoma (with a partial response), with the involvement of 0/6 lymph nodes. Post-operatively, the patient's blood AFP concentration was $64.8 \mathrm{ng} / \mathrm{ml}$. Following 3 cycles of FOLFIRI chemotherapy (as above), the patient experienced severe headaches. A CT scan revealed metastasis to the left occipital lobe. The patient underwent an emergency decompressive craniectomy and tumor resection on January 21, 2013, and the post-operative blood AFP concentration was $383.7 \mathrm{ng} / \mathrm{ml}$. In March 2013, a CT scan revealed that the lung and residual brain metastases had progressed, and there was additional suspicious testicular metastasis. The blood AFP concentration was $694.7 \mathrm{ng} / \mathrm{ml}$. The patient subsequently received palliative whole-brain radiotherapy (3,000 cGy in 10 fractions), following the completion of which, the AFP concentration was $3,350.7 \mathrm{ng} / \mathrm{ml}$. The patient was then administered 6 weeks of tegafur/gimeracil/oteracil potassium $\left(\mathrm{S}-1 ; 60 \mathrm{mg} / \mathrm{m}^{2}\right.$ orally twice daily 4 weeks) and ginsenoside $\mathrm{Rg} 3(20 \mathrm{mg} / \mathrm{m} 2$ orally twice daily 4 weeks). However, the residual brain and lung tumors progressed significantly, and a large supraclavicular lymph node metastasis was detected. On June 15, 2013, the patient's blood AFP concentration was $8,315.4 \mathrm{ng} / \mathrm{ml}$. The patient succumbed to a cerebral hernia on June 25, 2013. Histological images of the primary tumor and brain metastasis are shown in Fig. 1. Direct sequencing confirmed the wild-type K-RAS (codons 12 and 13), N-RAS (codons 12 and 13) and BRAF (V600E) gene types of primary cancer.

Case 3. A 62-year-old man was diagnosed with a sigmoid adenocarcinoma via colonoscopy at a local hospital on November 13, 2012. Blood tests indicated CA19-9 and AFP concentrations of $82.6 \mathrm{U} / \mathrm{ml}$ and $36,161.5 \mathrm{ng} / \mathrm{ml}$, with negative hepatitis markers. A CT scan revealed multiple liver tumors. A liver biopsy at our hospital revealed a poorly-differentiated adenocarcinoma with hepatocyte paraffin 1 (Hep par 1)(-), caudal type homeobox 2(-), cytokeratin (CK)19(+) and AFP(+) findings, which were considered to indicate metastasis. Blood tests showed CEA, CA 19-9 and AFP concentrations of $9.8 \mathrm{ng} / \mathrm{ml}, 104.5 \mathrm{U} / \mathrm{ml}$ and $>10,000 \mathrm{ng} / \mathrm{ml}$, respectively. The patient was recruited into a clinical trial of oxaliplatin $\left(130 \mathrm{mg} / \mathrm{m}^{2} \mathrm{IV}\right.$ over $2 \mathrm{~h}$ on day 1$)$ and $\mathrm{S} 1\left(60 \mathrm{mg} / \mathrm{m}^{2}\right.$ orally twice daily for 2 weeks; repeated every 3 weeks) for the treatment of metastatic colorectal cancer. Following 4 cycles of this treatment, the disease was observed to be stable, with blood CEA, CA 19-9 and AFP concentrations of $14.5 \mathrm{ng} / \mathrm{ml}, 116.0 \mathrm{U} / \mathrm{ml}$ and $5,717.1 \mathrm{ng} / \mathrm{ml}$, respectively. The patient experienced intestinal obstruction following the fifth cycle of chemotherapy, at which time the blood CEA, CA 19-9 and AFP concentrations were $16.5 \mathrm{ng} / \mathrm{ml}, 113.7 \mathrm{U} / \mathrm{ml}$ and $>10,000 \mathrm{ng} / \mathrm{ml}$, respectively. The patient subsequently underwent a palliative resection for the sigmoid adenocarcinoma on April 9, 2013. The pathology report indicated a moderately-differentiated colon adenocarcinoma, with the involvement of 10/17 lymph nodes. Immunohistochemical results were Hep par 1(+), CDX2(+++), CK19(+++) and AFP(++). On May 14, 2013, a CT scan revealed that the liver metastases had progressed significantly and the blood CEA, CA19-9 and AFP concentrations were $18.4 \mathrm{ng} / \mathrm{ml}$, $217.0 \mathrm{U} / \mathrm{ml}$ and $>10,000 \mathrm{ng} / \mathrm{ml}$, respectively. Subsequently, the patient was administered 5 cycles of FOLFIRI chemotherapy (see above), however, the liver metastases continued to progress significantly. The K-RAS gene was confirmed to be wild-type on direct sequencing. The patient was subsequently 


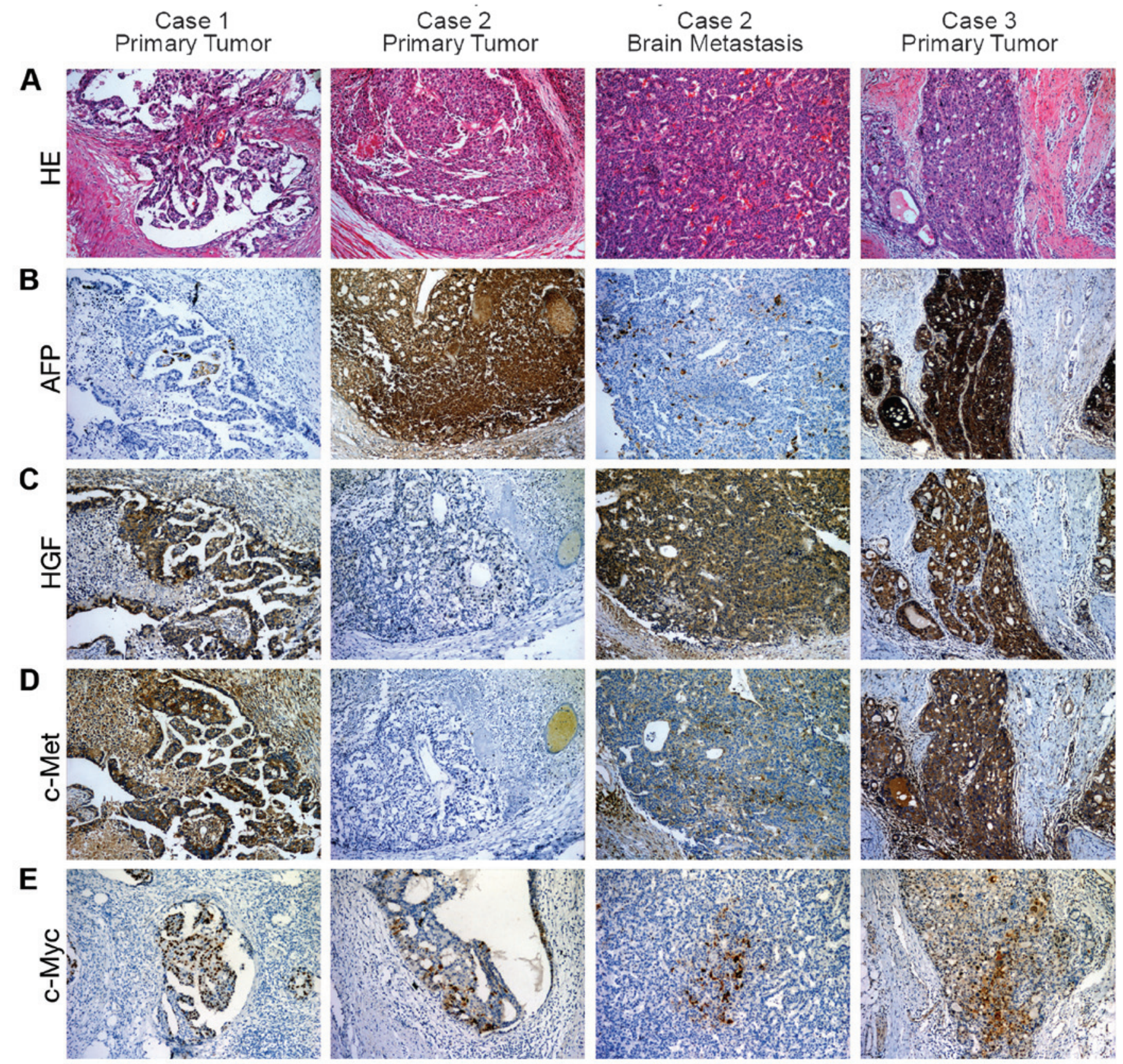

Figure 1. HE and immunohistochemical staining of AFP colorectal adenocarcinoma samples (magnification, x100). Column 1 represents case 1. (B) AFP expression in the adenocarcinoma is scattered. (C and D) HGF and c-Met are intensely stained in adenocarcinoma cells. Columns 2 and 3 represent the primary tumor following radiochemotherapy and the brain metastasis, respectively, of case 2. (A) In column 3, HE staining of the brain metastasis revealed classical histological hepatoid features. (C and D) In column 2, HGF and c-Met are negative in the primary tumor, whereas they are highly expressed in the brain metastasis sample in column 3. Column 4 represents case 3. (B, C and D) In column 4, AFP, HGF and c-Met are highly expressed. c-Myc is expressed in the adenocarcinoma cell nuclei of all 3 cases ( $E$ in all 4 columns). HE, hematoxylin and eosin; AFP, $\alpha$-fetoprotein-producing; HGF, hepatocyte growth factor.

administered 8 cycles of FOLFIRI and cetuximab chemotherapy (see above) until November 23, 2013, when a CT scan revealed that the disease was stable. However, the patient suffered from increasing liver pain. On October 31, 2013, a blood test showed CEA, CA 19-9 and AFP concentrations of $9.5 \mathrm{ng} / \mathrm{ml}, 154.9 \mathrm{U} / \mathrm{ml}$ and $74,336.9 \mathrm{ng} / \mathrm{ml}$, respectively. The patient succumbed to hepatic failure on January 2, 2014. Histological images of the primary tumor are presented in Fig. 1. Additional direct sequencing confirmed the wild-type N-RAS (codons 12 and 13) and BRAF (V600E) gene types of primary cancer.

\section{Discussion}

APA/HA was initially reported by Ishikura et al (5) in 1985; however, its incidence rate remains largely unknown due to the lack of a unified diagnostic standard. The majority of APA/HA cases arise from the gastrointestinal tract, particularly the stomach. Among gastric carcinomas, the proportion of APA/HAs has been reported to be $1-15 \%(1,2,4)$. In the USA, the overall incidence of gastric and colorectal cancers is $>50 / 100,000$ individuals (6). Therefore, if the proportion of APA/HAs is $1 \%$, the expected incidence of APA/HA would 
be $\sim 0.5 / 100,000$ individuals, which is equal to the incidence of gastrointestinal stromal tumors. Thus, APA/HA is a type of cancer that is frequently overlooked. A previous study with a small sample size suggested that HA with characteristic histological features possessed a poor prognosis, whether it was AFP-producing or not, and that HA should be distinguished from APA without hepatoid features (1). In the present study, only case 2 demonstrated classical histological hepatoid features. However, all 3 cases showed high levels of blood AFP and positive staining for AFP in the tumor tissue samples. We propose that hepatoid histological features or a positive immunohistochemical AFP finding is sufficient for a diagnosis of APA/HA.

The 3 cases of APA/HA in the present study all exhibited primary resistance to chemotherapy. As the disease progressed, the APA/HA component of the primary liver adenocarcinoma became more dominant, which was reflected in consistently elevated AFP concentrations, but reasonably stable levels of CEA and CA19-9. Although the 3 cases exhibited wild-type K-RAS (codons 12 and 13), N-RAS (codons 12 and 13) and BRAF (V600E), which was confirmed via direct sequencing, 2 of the patients (cases 1 and 3) who received cetuximab treatment demonstrated resistance to epidermal growth factor receptor (EGFR) inhibitors. The mechanisms of resistance for colorectal cancers exhibiting such gene types are complex (7). Liska et al (8) identified that the hepatocyte growth factor (HGF)/c-Met receptor kinase signaling pathway is able to induce resistance to anti-EGFR treatment via stimulation of the mitogen-activated protein kinase and AKT signaling pathway.

All 3 cases in the present study were identified to exhibit activation of the HGF/c-Met signaling pathway. In case 2, the primary tumor was negative for $\mathrm{HGF} / \mathrm{c}-\mathrm{Met}$ expression following radiochemotherapy; however, the brain metastasis was strongly positive for HGF/c-Met expression. The authors of the present study propose that HGF and c-Met tyrosine kinase activation may be the key signaling pathway via which APA/HA occurs. Paracrine HGF/c-Met activation is believed to contribute to oncogenesis and tumor progression in a number of cancers, and to promote aggressive cellular invasiveness, which is associated with tumor metastasis (9). Myofibroblast-secreted HGF is able to activate $\beta$-catenin-dependent transcription, and subsequently colon cancer stem cell clonogenicity. In addition, myofibroblast-secreted HGF is capable of restoring the cancer stem cell phenotype in more differentiated tumor cells (10). It has been demonstrated that HGF secreted by stromal cells is able to elicit an innate resistance to numerous anticancer drugs (11). However, the HGF in the present 3 cases was detected in adenocarcinoma cells and not stromal cells. As a result, we speculate that autocrine $\mathrm{HGF} / \mathrm{c}-$ Met activation may be able to induce dedifferentiation of common adenocarcinoma cells, which revert to a stem cancer cell phenotype and produce AFP or hepatoid differentiation. Consequently, therapy targeted to the HGF/c-Met signaling pathway may potentially be an effective treatment for APA/HA.

\section{Acknowledgements}

The present study was supported by the National Natural Science Foundation of China (grant no. 81301890), the Zhejiang Provincial Natural Science Foundation of China (grant nos. LY13H160010, 2012ZQ017) and the Fund of Public Welfare in Health Industry of China (grant no. 201402015). The authors would like to thank Content Ed Net, Shanghai Co., Ltd., (Shanghai, China) for providing editorial assistance with the manuscript.

\section{References}

1. Nagai E, Ueyama T, Yao T and Tsuneyoshi M: Hepatoid adenocarcinoma of the stomach. A clinicopathologic and immunohistochemical analysis. Cancer 72: 1827-1835, 1993.

2. Baek SK, Han SW, Oh DY, Im SA, Kim TY and Bang YJ: Clinicopathologic characteristics and treatment outcomes of hepatoid adenocarcinoma of the stomach, a rare but unique subtype of gastric cancer. BMC Gastroenterol 11: 56, 2011.

3. Bosman FT (ed); World Health Organization; International Agency for Research on Cancer. WHO classification of tumours of the digestive system. IARC Press, Lyon, 2010.

4. Su JS, Chen YT, Wang RC, Wu CY, Lee SW and Lee TY: Clinicopathological characteristics in the differential diagnosis of hepatoid adenocarcinoma: A literature review. World J Gastroenterol 19: 321-327, 2013.

5. Ishikura H, Fukasawa Y, Ogasawara K, Natori T, Tsukada Y and Aizawa M: An AFP-producing gastric carcinoma with features of hepatic differentiation. A case report. Cancer 56: 840-848, 1985.

6. Howlader N, Noone AM, Krapcho M, Garshell J, Neyman N, Altekruse SF, Kosary CL, Yu M, Ruhl J, Tatalovich Z, et al: (eds): SEER Cancer Statistics Review, 1975-2010. National Cancer Institute, Bethseda, MD, 2012.

7. Giampieri R, Scartozzi M, Del Prete M, Maccaroni E, Bittoni A, Faloppi L, Bianconi M, Cecchini L and Cascinu S: Molecular biomarkers of resistance to anti-EGFR treatment in metastatic colorectal cancer, from classical to innovation. Crit Rev Oncol Hematol 88: 272-283, 2013.

8. Liska D, Chen CT, Bachleitner-Hofmann T, Christensen JG and Weiser MR: HGF rescues colorectal cancer cells from EGFR inhibition via MET activation. Clin Cancer Res 17: 472-482, 2011.

9. Cecchi F, Rabe DC and Bottaro DP: Targeting the HGF/Met signalling pathway in cancer. Eur J Cancer 46: 1260-1270, 2010.

10. Vermeulen L, De Sousa E Melo F, van der Heijden M, Cameron K, de Jong JH, Borovski T, Tuynman JB, Todaro M, Merz $\mathrm{C}$, Rodermond $\mathrm{H}$, et al: Wnt activity defines colon cancer stem cells and is regulated by the microenvironment. Nat Cell Biol 12: 468-476, 2010.

11. Straussman R, Morikawa T, Shee K, Barzily-Rokni M, Qian ZR, Du J, Davis A, Mongare MM, Gould J, Frederick DT, et al: Tumour micro-environment elicits innate resistance to RAF inhibitors through HGF secretion. Nature 487: 500-504, 2012. 